\title{
Genetic Algorithm Based Power Control Strategies of a Grid Integrated Hybrid Distributed Generation System
}

\author{
T. Praveen Kumar ${ }^{1}$ N. Subrahmanyam ${ }^{1} \cdot$ Sydulu Maheswarapu ${ }^{1}$ \\ Received: 29 January 2021 / Accepted: 3 July 2021 / Published online: 26 August 2021 \\ (C) The Author(s), under exclusive licence to Springer Nature Singapore Pte Ltd. 2021
}

\begin{abstract}
In this manuscript, a genetic algorithm (GA) is proposed for the power management (PM) of a grid integrated hybrid distributed generation (DG) system. The hybrid distribution generation (DG) system incorporates photovoltaic (PV), wind turbine (WT), fuel cell (FC) and battery. The power fluctuations are produced in the distributed generation system, because the hybrid resource utilization and the generation of power is changeable. The major purpose of the proposed control method is "to control the power flow (PF) of active with reactive energy amid the source and grid side. The proposed GA-based power control system is mainly utilized for optimizing active with reactive power flow controllers. By controlling charge with discharge of battery, the proposed system met the energy requirement of the charge and managed the sensitivity of the charge. The proposed method provides an optimal power flow in DG systems. To evaluate the management of PF, the equality with inequality constraints is determined that is used to specify the accessibility of renewable energy sources (RES), the demand for electricity and storage components load level. The security of power system is improved with the help of proposed control system. Moreover, the battery is used to allow the renewable energy system and maintain a stable power output. The proposed method is activated in MATLAB / Simulink work site and the performance is compared with existing methods. The statistical analysis of mean, median and standard deviation (SD) are also analyzed for proposed with existing methods. The proposed technique mean value is 1.5784 , median is $1.4892, \mathrm{SD}$ is 0.5883 .
\end{abstract}

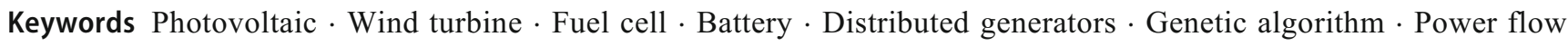
management $\cdot$ Source side control $\cdot$ Grid side control

\section{Introduction}

The world countries are met most of the total electricity demand through the power generated by the traditional power plants [16]. In the power generation process, major fossil fuels, like diesel, gas and coal are used as fuel to power turbines used [20,22]. These power generations based on fossil fuel release dangerous as well as toxic gases which causing harm in human health and animals $[15,35]$. Global warming is a major effect of these toxic gases produced by power plants [21]. Moreover, the fossil fuels availability is very low, but the requirement of energy consumption is growing rapidly [13,

T. Praveen Kumar

praveent0317@gmail.com

1 Electrical Engineering, National Institute of Technology, Warangal, Telangana, India
27]. Therefore, in the power generation process, these conventional fossil fuel based plants cannot be used for a long time $[25,32]$.

At present, the consumption of RES is growing at a faster pace because of the environmental issues in reducing greenhouse gases (GHG) that is broadly accepted as alternative electricity [28]. One of the major concepts of RES based on power generation is distributed generation [14]. The distributed generation is also called embedded generation, dispersed generation or decentralized generation [8]. The infrastructure of existing power grid must be developed as an advanced grid to meet the increasing power requirement, service quality demands and minimize the pollution, [18]. The distributed generation is considered as an important source for controlling power generation process and minimization of cost, which is also considered as alternatives of conventional power systems [36].

DG is directly linked with distribution network [6]; it is a small scale generation [9]. DG is based on the renewable 
energy sources (RES) which consist of PV, wind turbines, combustion gas turbines, biomass gasification, other small generation units etc. [5]. Compared to the conventional methods of the power generation, the DG has more advantages and it is installing in the place of the power demand [23]. But, every few kilo meter distance, it is impossible to set up a new power generation [19]. The DG technology does not produce the dangerous product, it does not affect the environment that mean s environment friendly and cost effective, it offers higher superior quality and reliability [11]. Recently, the hybrid RES has become increasingly based on lesser fuels costs as well as suggests a clean environment at any time of the year [37]. The RES like wind, solar generated electricity is speedily integrated with traditional power generation systems like microgrid [3]. Due to the integrated method, a hybrid distributed generation system is generated, which is most suitable for islanded power generation systems [38].

In this manuscript, a GA is proposed for the power management of a grid integrated hybrid DG system [34]. The hybrid distribution generation (DG) system incorporates PV, WT, FC and battery. The main intention of the proposed method is to control the power flow of active with reactive power among the source and grid side. The proposed GA-based power control system is employed to optimize the active with reactive power flow and controllers. The remaining segment of this manuscript is: Segment 2 presents the recent investigation works. Segment 3 explains the systems modeling with design analysis. Segment 4 illustrates the control strategy of the proposed system. Segment 5 explains about the proposed method. Segment 6 demonstrates the experimental results. Finally, Segment 7 concludes the manuscript.

\section{Recent Research Work: A Brief Review}

Several investigation works were already presented in the literature depending on the power management in the distribution system using various methods and features. Certain works are reviewed here,

Sultanaa et al. [30] have presented the Grasshopper Optimizer algorithm (GOA) for the voltage stability factor and the reduction of power loss was updated through the best allocation of Distributed Generation (DG) and BSS. The operating limits of loads, BSS and DG in every zone were considered for the transport systems 33 and 69. The GOA strategy was contrasted with conventional and notable strategies such as the gravitational search algorithm (GSA), artificial bee colony $(\mathrm{ABC})$ and particle swarm optimization (PSO). The outcomes have indicated the prevalence of GOA as far as framework execution and union qualities. The ideal sizes and destinations for DG-BSS situation on framework were gainful for electric vehicle clients, BSS designers, the power grid and utilities. Reddy et al. [25] have introduced Whale Optimization Algorithm for determining optimal DG-units size at distribution system. Unique hunting behaviors of humpback whales were utilized for modelling WOA. The purpose of the introduced method was diminishing in the active power loss of the system with development in the voltage profile of the system bus. An introduced method was applied to different DGs with radial distribution systems of 15, 33, 69, 85 and 118 buses. The power loss index method was used to achieve the DG location in optimal manner.

Sultana et al. [29] have introduced a capable enhancement approach depending on Gray Wolf Optimizer (GWO) for various DG designations at distribution system. Various targets were to limit the loss of reactive power and recover the distribution system voltage profile without violating the electrical system constraints. The GWO was contrasted by Gravitational Search Algorithm together with meta-heuristic strategies based on Bat Algorithm (BA). Distinctive contextual analyzes of different DG type assignments on 69-bus distribution system were completed to display feasibility of proposed technique and appropriation framework execution. Relative numerical outcomes, the voltage profile and characteristic of the convergence curves show the best performance of GWO next to GSA and BA.

Suresh et al. [31] have built up the new nature- inspired algorithm named Dragonfly algorithm for deciding the ideal size of DG unit. It depends on the unusual behavior of the dragonflies in nature. Dragonfly algorithm mostly focused on dragonflies how they look like to food or away from foes. Dragonfly algorithm was examined on IEEE 15, 33 and 69 test systems. Outcomes acquired through algorithm were contrasted by other developmental algorithms. When likened to different algorithms, Dragonfly algorithm provides the better outcomes. Sarker et al. [26] have introduced the unified power quality conditioner (UPQC) designation depending on the cuckoo optimization algorithm (COA) on three-stage unbalanced distribution system. The UPQC discussion was concentrated regarding minimization load disturbance during failure stage in test frames, $\%$ decrease of THD, individual harmonics, reduction of active power losses, diminishing voltage imbalance and increased cost reserve funds through ordinary working conditions. The COA exposure was contrasted to other delicate processing procedures with better outcomes.

Vatani et al. [33] have presented the analytical and genetic algorithm combination techniques were utilized for the optimal allocation of multiple DGs. The presented method combination ensures the precision and speed of convergence in the allocation of multiple DG units. The utility was only dictated the DG's maximum power generation if DG was put in with the owner of DG. Though, DG size and location was determined 
with the utility company if DG was installed with Hassan et al. [7] have suggested a Lagrangian genetic algorithm scaled up to optimal size and allotment of DG-based renewable energy sources.

The purpose of the introduced method was minimising the total system losses. The suggested method was used the Solar PV together with wind renewable energy systems and tested under two distribution networks. ALGA was solves a sequence of sub-problems of violation of operation constraints.

Omar et al. [17] have established a multiple objective economic-environmental dispatch (MOEED) method for incorporated thermal, natural gas, and renewable energy systems deeming the level of pollutant emission, total fuel or generation cost characteristics. Here, the 2 cases were done in IEEE 30-bus system by converting thermal generation units as natural gas units for diminishing the quantity of toxin emission with fuel cost. Equality, inequality like active, reactive powers, prohibited operating zones (POZs) which implies bad performance at the cost production process, also security constraints were deemed as system constraints. Natural gas units (NGUs) were structured in detail. So, the flow velocity of gas with pressure pipeline was determined into system constraints. Multi-objective Harris hawks optimization (MOHHO) and multi-objective flower pollination algorithm (MOFPA) were utilized to determine the Pareto optimal solutions (POSs) of fuel or generation cost and emission. Also, the technique for order preference by similarity to ideal solution (TOPSIS) was suggested to acquire the ideal value of POSs.

Rawa et al. [24] presented an economical-technicalenvironmental dispatch (ETED) method for adapted IEEE 30-bus system combined with thermal and combination of RESs. The aim of the presented method was overall fuel costs, active power losses, and lessening of emissions level. Various constraints of equality with inequality including POZs were defined as system constraints. To determine the optimum solution for the production cost, losses with emissions, the metaheuristic optimization methods, viz. moth-flame optimization, salp swarm algorithm, improved grey wolf optimizer, multi-verse optimizer have been utilized. Various scenarios were assessed to recognize the articulated optimization approach capability to solve the issue. A weighted sum strategy depending on analytic hierarchy process (AHP) was employed for converting the multi-objective issue as normalized single-objective one.

\section{Background of Research Work}

Detailed survey on the power management in distribution system has been done. Around there is a lot of scope to work. For the global climate change problem, renewable energy technologies are significant role of energy protection in future. The development of the current conventional or centralized generation on distributed generation, Smart and Micro Power Grids have huge potential for eliminating various problems related to green energy, energy protection and inconvenience of the old electrical system infrastructures. The RES are free available from wind, solar, etc., that is the greatest option to be a part of the electrical system distribution. The integration of distributed generation to energy systems causes some technical issues, viz. constancy of energy system, power quality. However, these problems can be minimized by using compensation techniques. There are numerous techniques have been executed for the identification and grouping of the DG problems of power system, for example the modified bat search algorithm, spatter swarm algorithm-cuckoo search algorithm etc. Thus, the active with reactive power control swing is difficult based on the use of 2 modifiable control parameters. This is an important issue, such as the power balance and the reserve power classification. To deal these issues, optimal identifying using trend-setting innovation is required. In interrelated works, some control procedures are displayed for addressing power management problems, these aforementioned impediments have inspired to do this research work.

\section{System Modelling}

Distributed power generation allows the power system to be interconnected at almost any point. The proposed hybrid distributed generation system (DGS) incorporated with PV, wind turbine, fuel cell, inverter, converter and battery. Figure 1 shows that system model of proposed hybrid distributed generation system. The interface among the PV and load is the inverter. The converter is used for transmit inconstant DC supply into the controlled DC supply. If the converter is connected to the grid, it acts as a current source, if it not have any power supply then it act as voltage source. Filters are used for reducing the harmonics. Based on the load demands, proper schedule as well as control was provided by the battery. Moreover, to prevent the battery from excess charging and fulfil the load demand, it is needed to optimize the battery charging and discharging limit [1].

The major purpose of proposed approach is to satisfy the energy demand of the load, manage load by controlling charging and discharging mechanisms, reduce the limit of charging, discharge the battery cycles.

\section{Modeling of PV Panels}

PV is used to generate electrical power. The electrical circuit of PV system is incorporated with the two resistors, diode and 
Fig. 1 Overall Architecture of proposed method
PV Panel

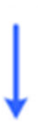

$D C-D C$

Converter
Wind Turbine

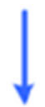

$D C-D C$

Converter
Fuel cell

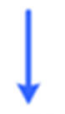

$D C-D C$

Converter
Battery

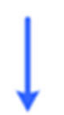

$D C-D C$

Converter
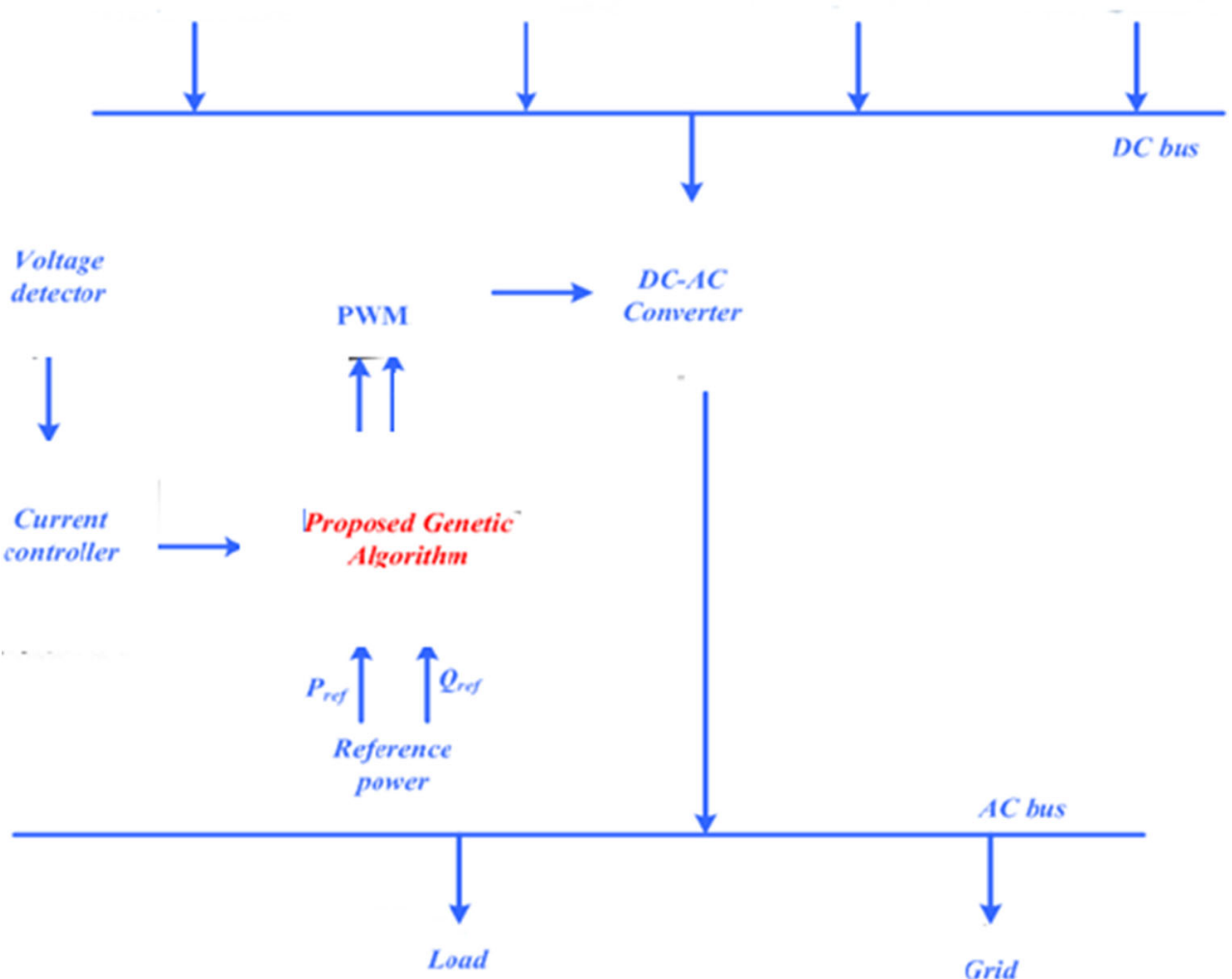

a current source. The current produced by PV model depending on the output voltage is described as,

$i_{p v}=i_{s c}\left[1-E_{1}\left(e^{\left(\frac{v_{p v}-\Delta v}{E_{2} v_{o c}}\right)}\right)-1\right]+\Delta i$

$E_{1}=\left(1-\frac{i_{m p p}}{i_{s c}}\right) e^{\frac{v m p p}{E_{2} v o c}}$

$E_{2}=\left[\frac{\left(\frac{v_{m p p}}{v_{o c}}\right)-1}{\ln \left(1-\frac{i_{m p p}}{i_{s c}}\right)}\right]$

here change of current is represented as $\Delta i$, Constants are represented as $E_{1}, E_{2}$, The change of current and voltage is described as,

$\Delta i=\alpha\left(\frac{\operatorname{Rad}}{\operatorname{Rad}_{\text {ref }}}\right) \Delta t+\left(\frac{\operatorname{Rad}}{\operatorname{Rad}_{\text {ref }}}-1\right) i_{s c}$
$\Delta v=-\beta \Delta t-r_{s} \Delta i$

$\Delta t=t-t_{r e f}$

here temperature coefficients is represented as $\alpha, \beta$, Solar radiation and radiation reference is represented as Rad, $_{\text {Rad }}$, , series resistance is represented as $r_{s}$, Short circuit current and peak current in maximal power point (MPP) is represented as $i_{s c}, i_{m p p}$. Open circuit voltage in MPP is represented $v_{o c}, v_{m p p}$. The short circuit current is described as,

$i_{s c}=\left[i_{s c}+k t\left(t_{c}-t_{n}\right)\right] \times \frac{g}{g_{n}}$

here temperature coefficient, calculated temperature, standard temperature is represented as $k t, t_{c}, t_{n}$, irradiance, standard irradiance is represented as $g, g_{n}$.

\section{Modeling of Wind Turbine}

In the hybrid DGS, the wind turbine (WT) is other important energy source. The electrical energy is created depending on 
speed of wind. Rated speed, cut in speed, cut out speed are the important types of wind speed. The wind turbine power is obtained from the rate of change of the kinetic energy that is expressed as,

$P=\frac{d E}{d t}=\frac{1}{2} \frac{d m_{a}}{d t} v_{W}^{2}$

here the mass flow rate is specified as $\frac{d m_{a}}{d t}=\rho a v_{W}$, wind area is denoted as $a$, air density is denoted as $\rho$, The above equation is rewritten as,

$P=\frac{1}{2} \rho a v_{W}^{3}$

By the determination of wind powers flowing in upstream and downstream is used to determine the extracted mechanical power which is determined as,

$P_{W}=\frac{1}{2} \rho a v_{W}\left(v_{U}^{2}-v_{D}^{2}\right)$

here velocity of wind in upstream is denoted as $v_{U}$, velocity of wind in downstream is denoted as $v_{D}$. The above equation is rewritten as,

$P_{W}=\frac{1}{2} \rho a r_{p} v^{3}$

here mechanical power in the air flow is denoted as $P_{W}$, power coefficient is denoted as $r_{p}$ which is depend on tip speed ratio, blade pitch angle.

\section{Fuel Cell}

Chemical energy is converted into electric energy by a fuel cell (FC). The process of FC is similar to battery. Though, until supplied with hydrogen and oxygen FC generate DC power continuously. Due to the high effectiveness, flexibility and simple operation, FC is used in DGS. The fuel cell voltage is determined as,

$v_{F C}=n_{f c}\left[v_{0}+\frac{U_{g} T}{2 F}\left(\ln \left(\frac{P_{\mathrm{H}_{2}} P_{\mathrm{O}_{2}}^{1 / 2}}{P_{\mathrm{H}_{2} \mathrm{O}}}\right)\right)-r_{i} i_{f c}\right]$

here number of fuel cells connected in series is denoted as $n_{f c}$, universal gas constant is denoted as $U_{g}$, free energy voltage is denoted as $v_{0}$,temperature is denoted as $T$, current through the fuel cell stack is denoted as $i_{f c}$, Faraday constant is denoted as $F$,partial pressures of hydrogen, water and oxygen is denoted as $P_{\mathrm{H}_{2}}, P_{\mathrm{O}_{2}}, P_{\mathrm{H}_{2} \mathrm{O}}$ respectively.

\section{Batteries}

In the hybrid DGS, batteries are used for energy storage units and perform as backup energy sources. In battery management one of the important challenges is discharging batteries under a certain level of charge is cause considerable damage to battery life by reducing the number of cycles. Depth of discharge (DOD) has lesser SOC level of the battery; hence, battery supply power among the entire SOC and DOD. The minimum capacity of battery is described as,

$E_{b \min }=(1-d o d) E_{b \max }$

The energy of the battery with respect to time is described as,

$E_{b(t)}=E_{b(t-1)}(1-\tau)+\left[E_{w t, p v(t)}-\frac{E_{l(t)}}{\eta_{b}}\right] \eta_{r t}$

here the previous hour of energy is stored at battery is denoted as $E_{b(t-1)}$, hourly self-discharge rate of the batteries is denoted as $\tau$, energy created at hour through wind turbine and PV panels is denoted as $E_{w t, p v(t)}$, the load which requires the power supply from the battery is denoted as $E_{l(t)}$, efficiency of the battery is denoted as $\eta_{b}$, round trip efficiency of the battery is denoted as $\eta_{r t}$. The power supplied or consumed by the battery is described as,

$P_{b(t)}=E_{w t, p v(t)}-E_{l(t)}$

\section{System Control Strategy}

The control diagram of distributed system is shown on Fig. 2. Using power conversion unit, an input power is changed into electricity. The produced electricity is distributed to grid that is depending on where the generation system is connected [2]. One of the important parts of the hybrid DGS is "its control". There are two types of control: input side control and grid side control.

\section{Input Side Control}

For obtaining the maximal power as input sources like renewable energy systems is the important part of the input side control. The maximal power point tracking (MPPT) and generator speed control is employed for obtaining the maximal power of PV and wind.

\section{Grid Side Control}

The grid-side control mode is to control the active power flow in the direction of grid, control the reactive power among hybrid DGS, control the voltage across the DC link, supply quality voltage to customers, frequency control. 
Fig. 2 Flow chart of proposed Genetic algorithm

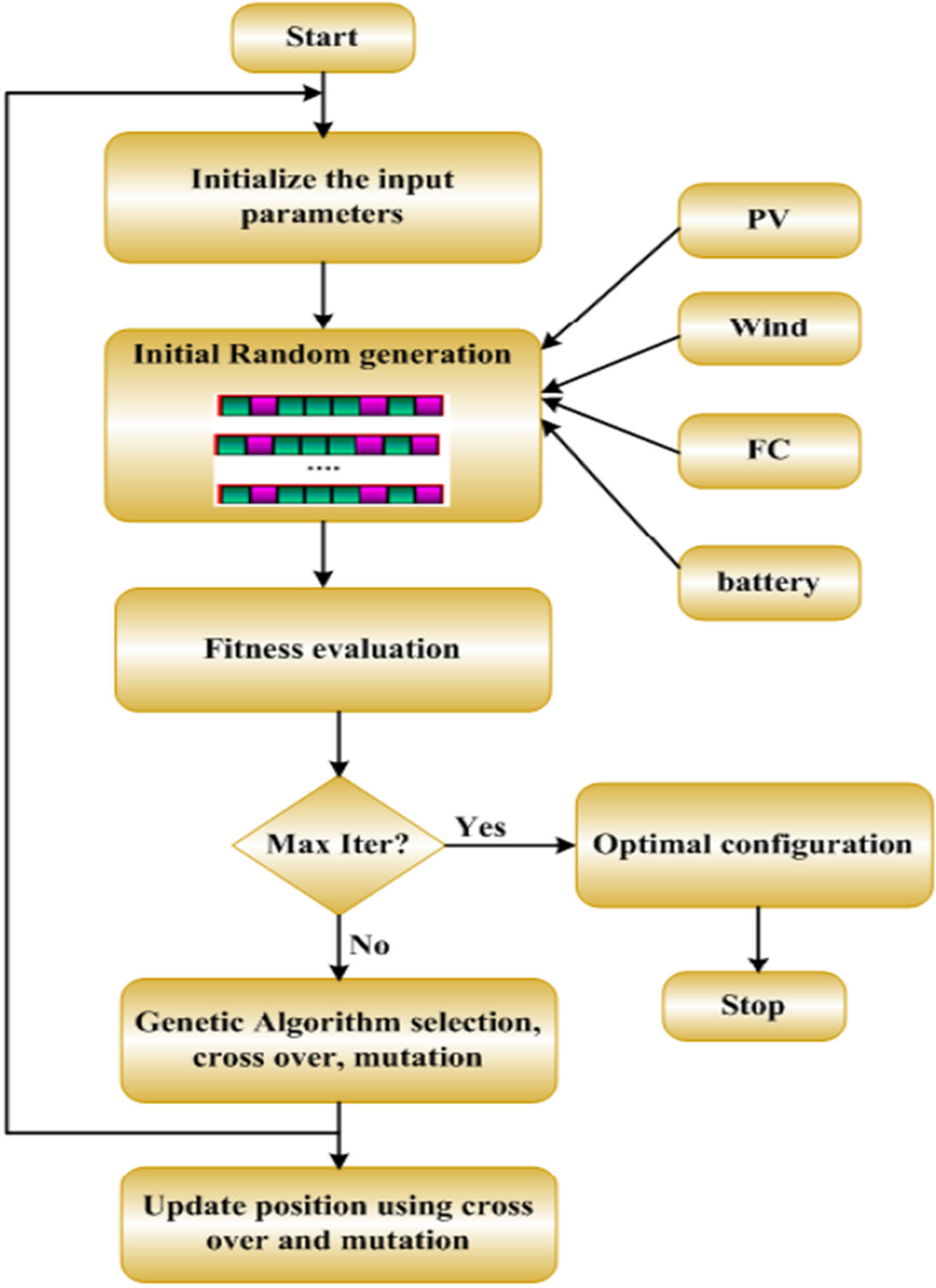

\section{Power Flow Control Strategies}

Based on the load, the power distributed by main grid and hybrid DGS should be controlled. For necessary control of the power flow amid the load and hybrid DGS, consider the constant active with reactive power is deemed [10]. The power balance is controlled as grid to the load and from storage devices when providing the required active with reactive power is delivered to the load. The total power available as distributed power source is described as,

$$
P_{d g s}(s)=P_{w t}(s)+P_{p v}(s)+P_{f c}(s)+P_{b}(s)
$$

To achieve the power balance, the grid power is exhibited in the given equation,

$P_{g r}(s)=P_{l}(s)-P_{d g s}(s)$

The reactive power is described by,

$Q_{g r}(s)=Q_{l}(s)-Q_{d g s}(s)$ 
When the charging time of battery considered as the energy stored in the battery represents power source, also storage battery power as load. The power produced is conveyed to the load is described as,

$P_{d c}(s)=C_{d c}\left(\frac{d v_{d c}}{d t}\right) v_{d c}$

$P_{d c}(s)=P_{d g s}(s)-P_{g r}(s)$

here DC connection power in time $t$ implies $P_{d c}(s)$, DC link voltage is denoted as $v_{d c}$, and DC link capacitance denoted as $C_{d c}$. Because of the uncertainties of the RES and nonlinearities related with the load, the power balance is difficult one [4]. To achieve the effective control in this paper proposed genetic algorithm based power control strategy.

\section{Constraints}

\section{Power Balance Constraint}

Power balance is the significant factor for fulfilling the load requirement with losses, When balance the system power, it presents system stability at a decreased cost. The power balance consists of active with reactive power are expressed as,

$P_{d i}^{D}=P_{g i}^{D}-Y_{i j} \sum_{i=j=1}^{N} V_{i} V_{j} \cos \left(v_{i}-v_{j}-\theta_{i}\right)$

$Q_{d i}^{D}=Q_{g i}^{D}-Y_{i j} \sum_{i=j=1}^{N} V_{i} V_{j} \sin \left(v_{i}-v_{j}-\theta_{i}\right)$

where power productions of generators on bus $i$ implicates $P_{g i}^{D}$ and $Q_{g i}^{D}$, admittance of the line among $i$ and $j$ signifies $Y_{i j}$, bus phase angle $i$ implies $\theta_{i}$, load requirement in bus $j$ denotes $P_{d i}^{D}$ and $Q_{d i}^{D}$, the limit of active with reactive power is,

$P_{d i}^{D(\min )} \leq P_{d i}^{D} \leq P_{d i}^{D(\max )}$ and $Q_{d i}^{D(\min )} \leq Q_{d i}^{D} \leq Q_{d i}^{D(\max )}$

\section{Voltage Restriction}

This is must be within a certain range of voltage. This is ranged amid the minimal and maximal voltage. The bus $\mathrm{i}$ voltage range is,

$V^{m n} \leq V_{i} \leq V^{m x}$

where minimum with maximum values for voltage on bus $i$ denotes $V^{m n}$ and $V^{m x}$.

\section{(iii) DG constraint.}

This is based upon optimum capacity of buses including the power factor of DG. The DG capacity is computed by the eq. (22).

$$
\sum_{i \in N} \sqrt{\left(P_{i}^{D G}\right)^{2}+\left(Q_{i}^{D G}\right)^{2}} \leq \frac{1}{2} \sum_{i \in N} \sqrt{\left(P_{i}^{L}\right)^{2}+\left(Q_{i}^{L}\right)^{2}}
$$

$p f_{\min }^{D G} \leq p f_{i}^{D G} \leq p f_{\max }^{D G}$

where at DG busi, the power factor minimum with maximum values denotes $p f_{\min }^{D G}$ and $p f_{\max }^{D G}$.

\section{Power Flow Management Using Genetic Algorithm (GA)}

This segment describes the power management of active with reactive power of the hybrid DGS system. Here, a genetic algorithm is proposed for obtaining the balanced power of hybrid DGS system. The proposed GA-based power control system is utilized for optimizing active with reactive power flow controllers. The proposed method provides an optimal power flow in DG systems. To evaluate the PF management, describe the constraints of equality with inequality is determined that is used to specify the accessibility of RES, the demand for electricity as well as level of load of the storage components. One of the efficient bio-inspired algorithms is genetic algorithm which is used to determine both the constrained and unconstrained optimization issues [12]. In this proposed method GA is used for balancing active with reactive power.

\section{Step by Step Procedure of Genetic Algorithm}

\section{Step 1: Initialization}

Initialize the input parameters of active with reactive power that consists of PV, wind battery and FC model.

\section{Step 2: Random Generation}

The random function is used to generate the number between $[0,1]$. Based on the problem domain, the lower limit and the upper limit are selected.

\section{Step 3: Fitness Evaluation}

Determine the fitness of the each search agent. The evaluation of fitness is determined from the objective function. It is determined from,

The objective function is

$F_{j}=\min (\delta e(x))$

$\delta e(x)=P_{r e f}(s)-P_{i}(s), \quad Q_{r e f}(s)-Q_{i}(s)$

here system error function denotes $\delta e(x)$. 


\section{Step 4: Crossover Process}

In this process first select the parents for the operation of crossover and produce the new population based on this operation. Then check the fitness of each population and go to step 3 .

\section{Step 5: Mutation Process}

In the mutation process select the parents for the operation of mutation and produce the new population based on this operation. Then check the fitness of each population and go to step 3 .

\section{Step 6: Position Updation}

Update the position based on crossover as well as mutation operation.

\section{Step 7: Termination Criteria}

If the stopping termination criteria satisfy, then find the optimal solution, otherwise go to step 1. The flow chart of the power control management using genetic algorithm is illustrated in Fig. 2.

\section{Results and Discussions}

This segment describes the power control strategy based on genetic algorithms is proposed on this section. The proposed method is activated in MATLAB / Simulink site. The major intention of the proposed approach intention is to obtain an optimal power flow under hybrid DGS unit. The efficiency of the proposed GA system is assessed to compensate the variations on gridconnected hybrid DGS caused by the load. The performance of proposed approach is evaluated in three different cases.

\section{Case 1: Balanced Supply in Unbalanced Load Condition}

Here, the performance of the proposed system is analyzed based on the balanced supply in unbalanced load condition.
Based on the time domain this case is analyzed for power of photovoltaic, wind, FC, battery. Figure 3 shows the irradiance of PV system. The irradiance is constant to $1000 \mathrm{~W} / \mathrm{m}^{2}$ at the entire process. Figure 4(a) portrays that PV output power system. The power of PV is varies from 0 to $5400 \mathrm{~W}$ at the time of $0.01 \mathrm{~s}$. Then it reduces to $4500 \mathrm{~W}$ at the time of $0.1 \mathrm{~s}$. The power varied between 4400 to $4600 \mathrm{~W}$ after the time of $0.21 \mathrm{~s}$ to $1 \mathrm{~s}$. Figure 4(b) shows that WT output power system. The power of wind is varies from 0 to $3400 \mathrm{~W}$ at the time of $0.02 \mathrm{~s}$. then power is diminished from 3400 to below 2500 at the time of $0.1 \mathrm{~s}$. then it is slightly varied to 2300 to 2400 at the entire operation of the system. Figure 4(c) shows that FC output power. FC power is varies from 0 to $1400 \mathrm{~W}$ at $0.01 \mathrm{~s}$. Then the power is decreased to 0 at $0.03 \mathrm{~s}$. After that it gradually increased to reach above 2700 at $0.25 \mathrm{~s}$. After that it increased to reach $3000 \mathrm{~W}$ from the time of 0.7 to $1 \mathrm{~s}$.

Figure 4(d) shows that battery output power system. The power of battery is varies from 0 to $11,000 \mathrm{~W}$ at $0.01 \mathrm{~s}$. time interval then power is reduced from 11,000 to 0 at the time of $0.02 \mathrm{~s}$. then it is gradually increased to reach $4900 \mathrm{~W}$ at $0.25 \mathrm{~s}$. Afterward, it is slightly decreased to reach $4000 \mathrm{~W}$ at time of $0.27 \mathrm{~s}$. From the time of 0.27 to $1 \mathrm{~s}$ it is varied around $4000 \mathrm{~W}$. Figure 5(a) shows the analysis of load power under unbalanced condition. The load power is varies from 0 to $1.9 \times 10^{4}$ Wat 0.01 to $0.25 \mathrm{~s}$ time interval. Then the power is reduced from $1.9 \times 10^{4} \mathrm{~W}$ to $1.75 \times 10^{4} \mathrm{~W}$ at $0.3 \mathrm{~s}$ time interval. Then it is stable from 0.3 to $0.75 \mathrm{~s}$. After that, it is slightly increased to reach $2.3 \times 10^{4} \mathrm{~W}$ at time of 0.75 to $0.9 \mathrm{~s}$. then it decreased to reach $1.8 \times 10^{4}$ Wat 0.9 to $1 \mathrm{~s}$.

Figure 5(b) shows the analysis of total power under unbalanced load condition. The total power is varies from 0 to $1.9 \times 10^{4}$ Wat $0.01 \mathrm{~s}$ time interval. Then the power is reduced $1.9 \times 10^{4}$ Wto $0.39 \times 10^{4}$ Wat $0.03 \mathrm{~s}$ time interval. Then it is increased to reach $1.92 \times 10^{4}$ Wat $0.25 \mathrm{~s}$. After that it slightly decreased to reach 1.8 to $1.85 \times 10^{4} \mathrm{~W}$ at $0.26 \mathrm{~s}$. Then it is constant from 0.26 to $1 \mathrm{~s}$. Figure 6 portrays that comparison of total power for GA and PI. Here, proposed model total power attains high compared to the existing approach PI. From the simulation results of load power and total power that the proposed approach attains stability in a low duration of time and significantly reduces the distortion level in the output power.

Fig. 3 Analysis of PV irradiance

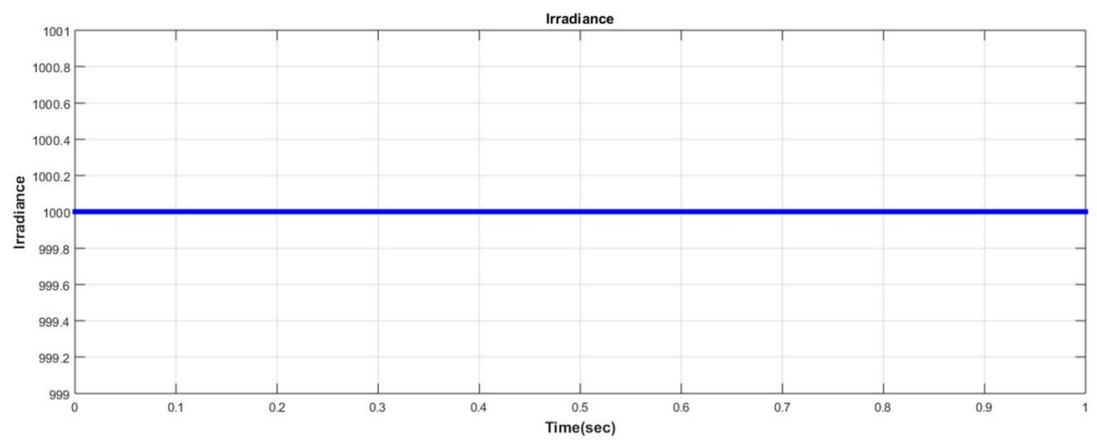




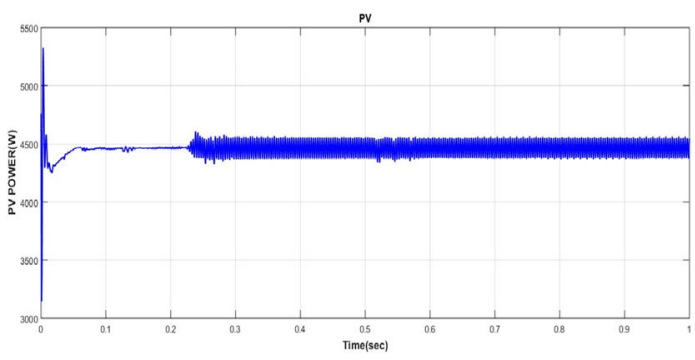

(a)

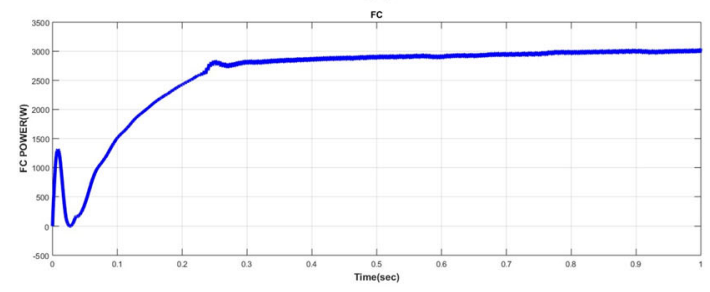

(c)

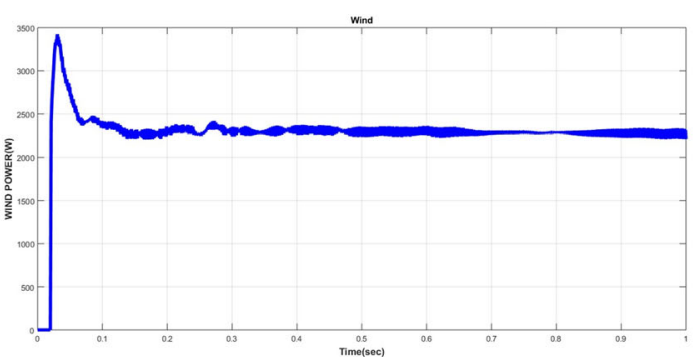

(b)

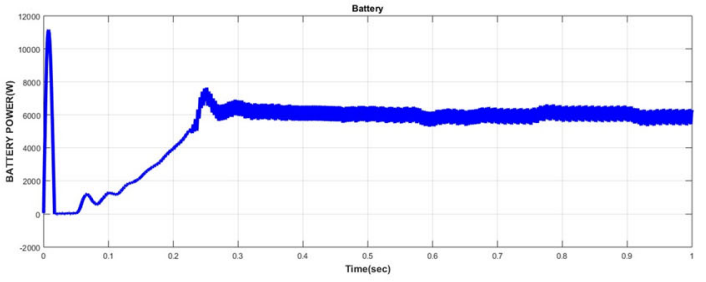

(d)

Fig. 4 Analysis of output power of (a) PV system (b) wind turbine (c) FC (d) battery

\section{Case 2: Step Variation on PV with Symmetric Load Condition}

The PV system with stepped variation is delivered at equilibrium load state by the input of the system and the changes in the output power of photovoltaic, wind, FC and battery systems are analyzed. Figure 7 demonstrates that photovoltaic system irradiance. The irradiance is $1000 \mathrm{~W} / \mathrm{m}^{2}$ at 0 to $0.75 \mathrm{~s}$ time interval then it is changed to $500 \mathrm{~W} / \mathrm{m}^{2}$ at $0.75 \mathrm{~s}$ to $0.9 \mathrm{~s}$ time interval. Then it is increased to $1000 \mathrm{~W} / \mathrm{m}^{2}$ at 0.9 to $1 \mathrm{~s}$.

Figure 8(a) demonstrates that output power analysis of PV system. Figure 8(b) shows the analysis of output power of the WT system with step variation. Figure 8(c) demonstrates that output power of FC with step variation in PV. Figure 8(d) shows the analysis of output power of battery system with step variation. Figure 9(a) shows the analysis of load power with step variation in PV. The load power is varies from 0 to $1.9 \times 10^{4} \mathrm{Wat} 0.01$ to $0.25 \mathrm{~s}$ time. Then power is reduced from $1.9 \times 10^{4} \mathrm{~W}$ to $1.75 \times 10^{4} \mathrm{~W}$ at $0.3 \mathrm{~s}$ time. Then it is stable from 0.3 to $1 \mathrm{~s}$. Figure 9 (b) portrays that analysis of total power under unbalanced load condition. The total power varies from 0 to $1.9 \times 10^{4} \mathrm{~W}$ at $0.01 \mathrm{~s}$ time. Then the power is reduced $1.9 \times 10^{4} \mathrm{~W}$ to $0.39 \times 10^{4} \mathrm{Wat} 0.03 \mathrm{~s}$ time. Then it is increased to reach above $1.9 \times 10^{4} W$ at $0.25 \mathrm{~s}$. After that it slightly decreased to reach 1.8 to $1.85 \times 10^{4} \mathrm{~W}$ at $0.26 \mathrm{~s}$. Then it is constant from
0.26 to $0.75 \mathrm{~s}$. At $0.75 \mathrm{~s}-0.9 \mathrm{~s}$, the power has been decreased to $1.59 \times 10^{4} \mathrm{~W}$. Then it maximized to reach $1.8 \times 10^{4} \mathrm{~W}$.

Figure 10 shows the comparison of total power with step variation in PV for GA and PI. Here the proposed method total power is high compared to the existing approach PI. From the simulation results of load power and total power that the proposed approach attains stability in a low duration of time and significantly reduces the distortion level in the output power.

\section{Case 3: Zero Response on PV under Balanced Load Condition}

The input sources are unbalanced and PV irradiance is changed to zero response to determine the optimal power flow in hybrid DGS. Figure 11 shows the PV irradiance changed to zero value.

Figure 11 shows analysis of PV at zero irradiance. The irradiance is $1000 \mathrm{~W} / \mathrm{m}^{2}$ at 0 to $0.75 \mathrm{~s}$ time interval then it is changed to $0 \mathrm{~W} / \mathrm{m}^{2}$ at $0.75 \mathrm{~s}$ to $1 \mathrm{~s}$ time. Figure 12(a) shows the analysis of output power of the PV system with zero response in $\mathrm{PV}$. The power of $\mathrm{PV}$ is varies from $5400 \mathrm{~W}$ at the time of $0.01 \mathrm{~s}$. Then it reduces to $4500 \mathrm{~W}$ at the time of $0.1 \mathrm{~s}$ to $0.25 \mathrm{~s}$. Then it slightly increased from 0.25 to $0.7 \mathrm{~s}$. At 0.7 to $1 \mathrm{~s}$ the power of PV indicates zero. Figure 12(b) shows that analysis of output power of WT system with zero response in PV.
Fig. 5 Analysis of (a) load power under unbalanced load condition (b) Total power under unbalanced load condition

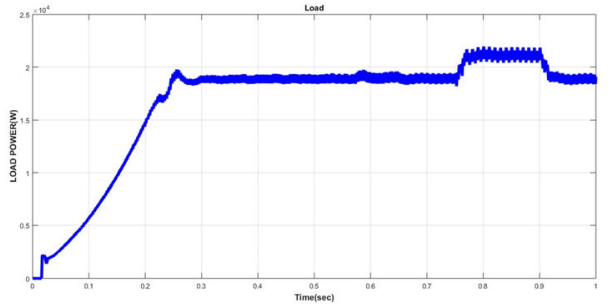

(a)

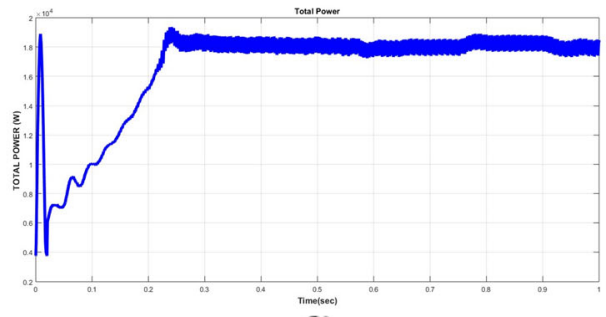

Timel(soc) 
Fig. 6 Comparison of total power of proposed and existing approach

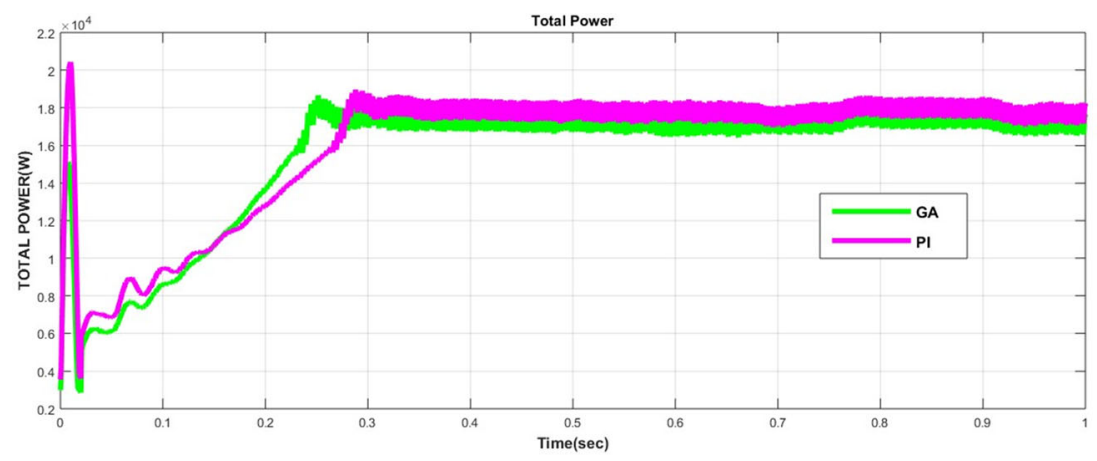

The power of wind is varies from 0 to $3400 \mathrm{~W}$ at the time of $0.02 \mathrm{~s}$. then power decreased from 3400 to below 2500 at the time of $0.1 \mathrm{~s}$. then it is slightly varied to 2300 to 2400 at the entire operation of the system. Figure 12(c) displays the analysis of output power of FC for zero response in PV. The FC power is varies from 0 to $1400 \mathrm{~W}$ at $0.01 \mathrm{~s}$. Then the power is decreased to 0 at $0.03 \mathrm{~s}$. After that it gradually increased to reach above 2700 at $0.25 \mathrm{~s}$. After that it increased to reach $3000 \mathrm{~W}$ from the time of 0.7 to $1 \mathrm{~s}$.

Figure 12(d) portrays the battery system output power analysis with zero response in PV. The power of battery is varies from 0 to $11,000 \mathrm{~W}$ at $0.01 \mathrm{~s}$ time. Then power is reduced from 11,000 to 0 at the time of $0.02 \mathrm{~s}$ then it is increased to reach above $7000 \mathrm{~W}$ at $0.25 \mathrm{~s}$. After that, it is slightly decreased to reach $6000 \mathrm{~W}$ at time of $0.27 \mathrm{~s}$. From the time of 0.27 to $1 \mathrm{~s}$ it is varied around $6000 \mathrm{~W}$. Figure 13 (a) shows the analysis of load power with zero response in PV. The load power is varies from 0 to $1.9 \times 10^{4} W$ at 0.01 to $0.25 \mathrm{~s}$ time. Then power is reduced from $1.9 \times 10^{4} W$ to $1.8 \times 10^{4} W$ at $0.3 \mathrm{~s}$ time. Then it is stable from 0.3 to $1 \mathrm{~s}$. Figure 13 (b) shows the analysis of total power with zero response in PV. The total power is varies from $0.4 \times 10^{4} \mathrm{~W}$ to $1.9 \times 10^{4} \mathrm{~W}$ at $0.01 \mathrm{~s}$ time. Then power is reduced $1.9 \times 10^{4} \mathrm{~W}$ to $0.39 \times 10^{4} \mathrm{Wat} 0.03 \mathrm{~s}$ time. Then it is increased to reach above $1.9 \times 10^{4} \mathrm{Wat} 0.23 \mathrm{~s}$. After that it slightly decreased to reach 1.8 to $1.85 \times 10^{4} \mathrm{~W}$ at $0.24 \mathrm{~s}$. Then it is constant from 0.26 to $0.75 \mathrm{~s}$. At $0.75 \mathrm{~s}$ to $1 \mathrm{~s}$ the power is reduced to $1.5 \times 10^{4} \mathrm{~W}$. Figure 14 shows the comparison of total power with step variation in PV for GA and PI. The settling time of existing strategies such as genetic algorithm (GA), and PI are $\mathrm{t}=0.38 \mathrm{~s}$ and $0.44 \mathrm{~s}$ respectively. Here, the proposed model total power is greater likened to the existing PI model. From the simulation results of load power and total power that the proposed approach attains stability in a low duration of time and significantly reduces the distortion level in the output power.

Table 1 illustrated the power of various sources. The PV system the power rating is $4.5 \mathrm{~kW}$. The WT system the power rating is $2.5 \mathrm{~kW}$. The FC system the power rating is $3.0 \mathrm{~kW}$. The battery system the power rating is $6.0 \mathrm{~kW}$. Table 2 displays the statistical analysis of proposed with existing methods.

\section{Conclusion}

In this manuscript, GA is proposed for the power management of a grid integrated hybrid DG system. The proposed model significantly reduces the system congestion and improves the system reliability and produces inflated power which increases the efficiency of the generation systems. The proposed approach is used to achieve an efficiency control strategy for regulating the flow of active with reactive power between the load and grid. GA optimizes active with reactive power flow and controllers. The efficiency of the proposed approach is analyzed by three different case analyzes. On observing the

Fig. 7 Analysis of PV irradiance

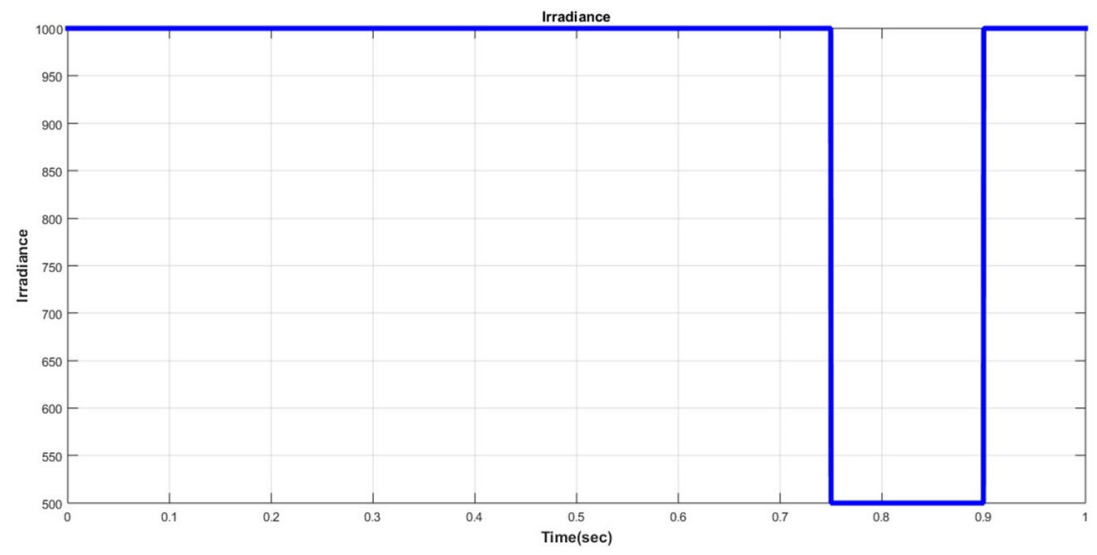




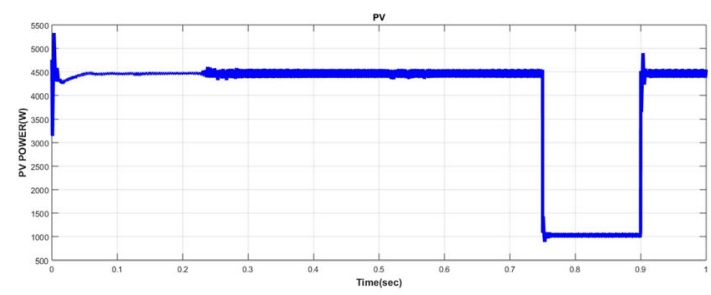

(a)

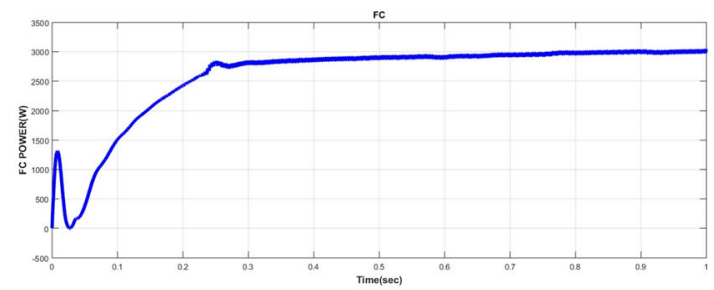

(c)

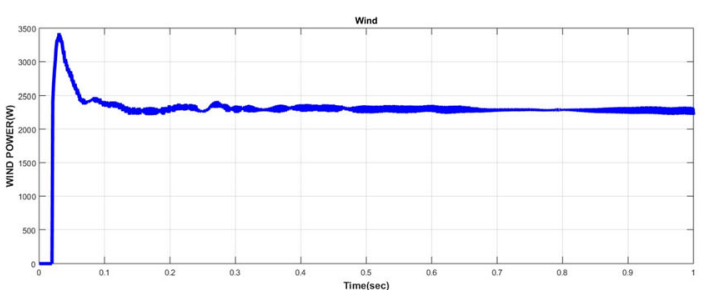

(b)

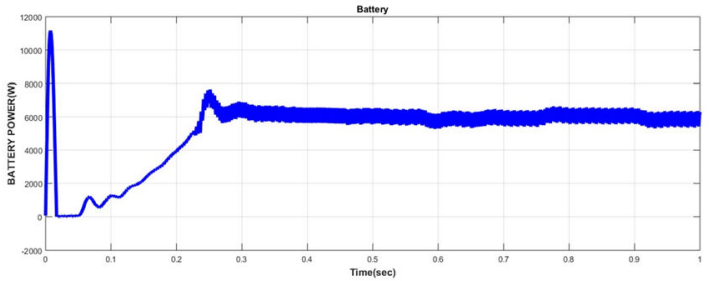

(d)

Fig. 8 Output power analysis of sources along step variation (a) PV (b) wind (c) FC (d) Battery

Fig. 9 Analysis of (a) load power with step variation in PV (b) total power with step variation in PV

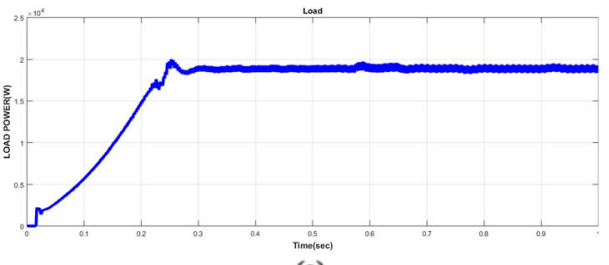

(a)

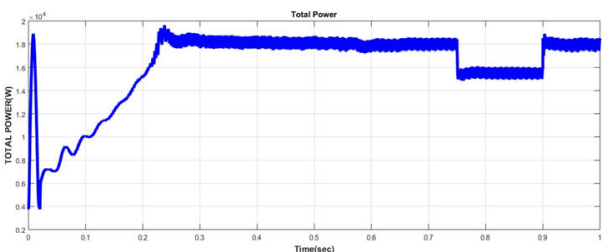

(b)
Fig. 10 Comparison of total power with step variation in PV for proposed and existing approach

Fig. 11 Analysis of PV at zero irradiance
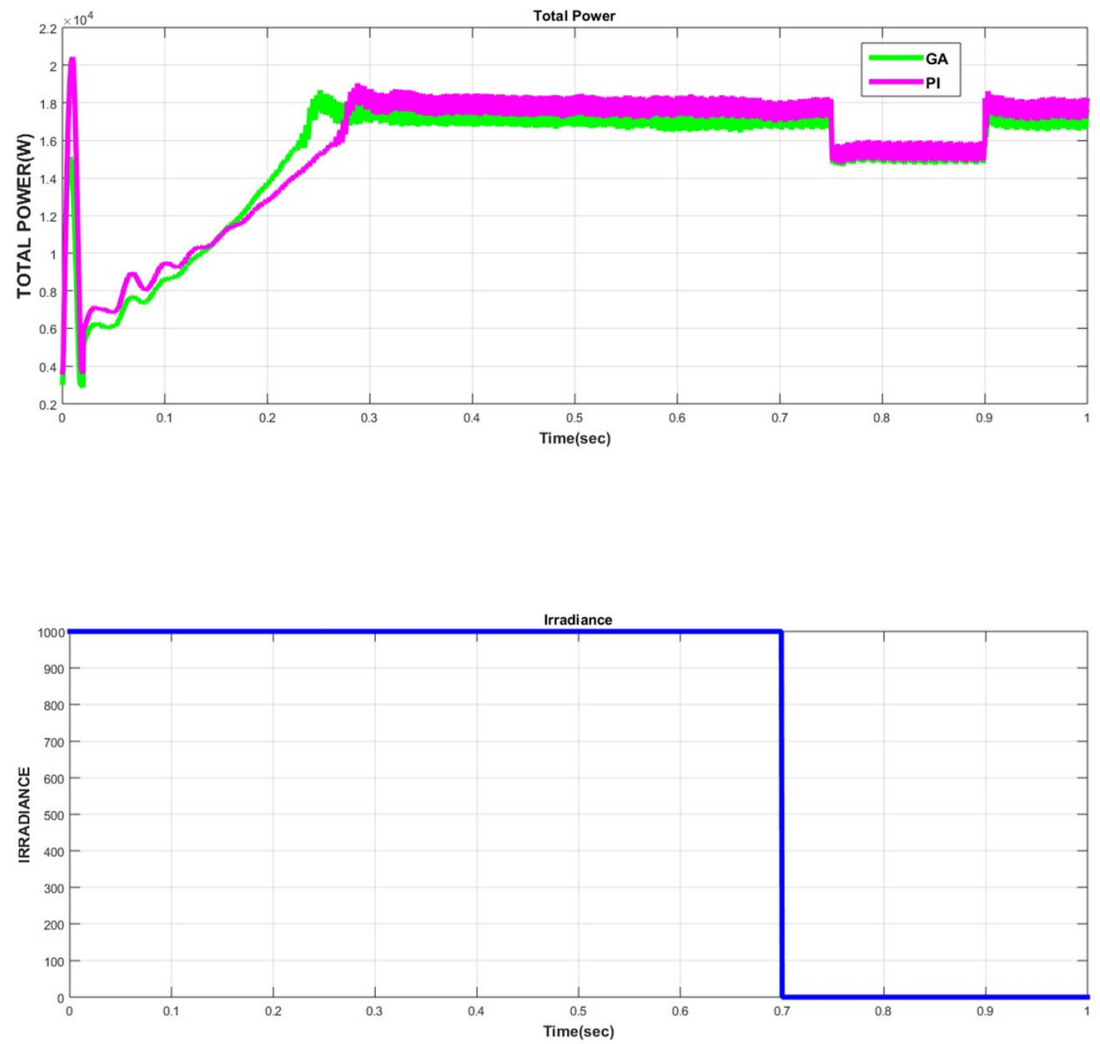


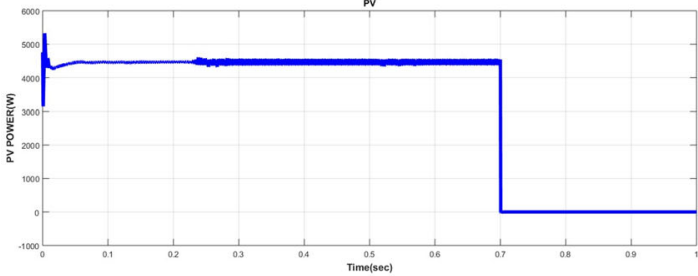

(a)

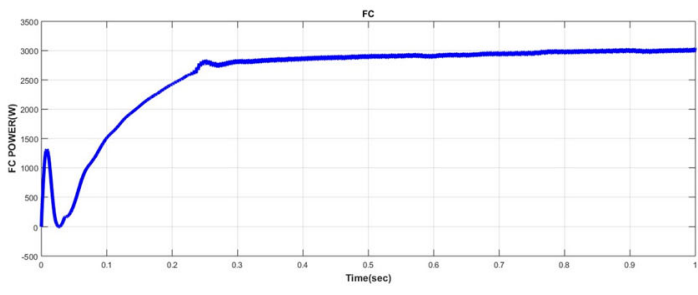

(c)

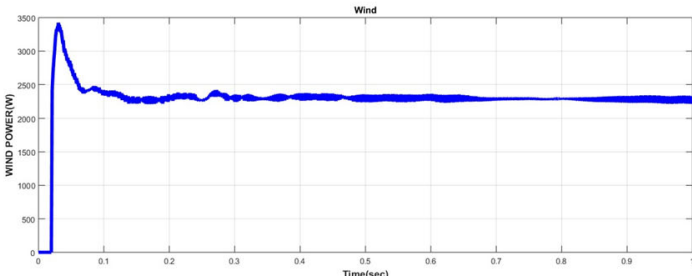

(b)

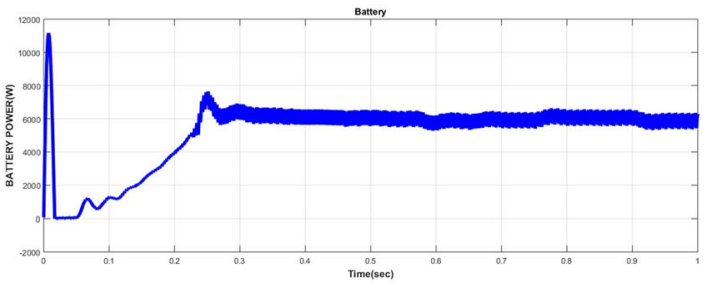

(d)

Fig. 12 Analysis of output power of sources with zero response (a) PV (b) wind (c) FC (d) Battery

Fig. 13 Analysis of (a) Load power for zero response (b) total power for zero response in PV
Fig. 14 Comparison of total power with step variation in PV of proposed and existing approach

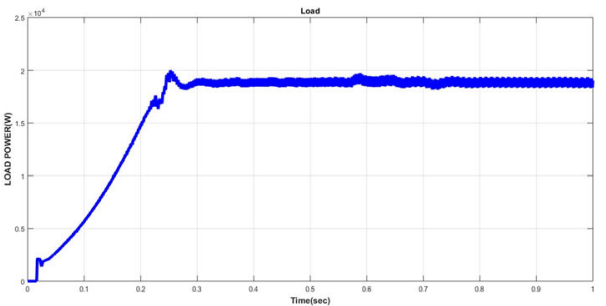

(a)

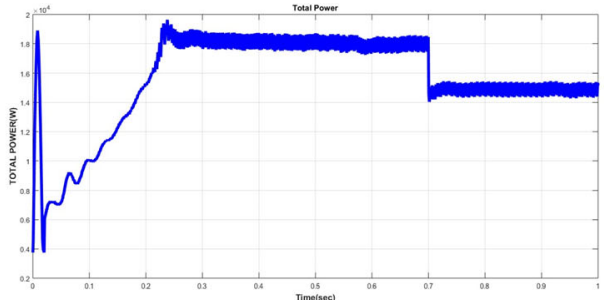

(b)

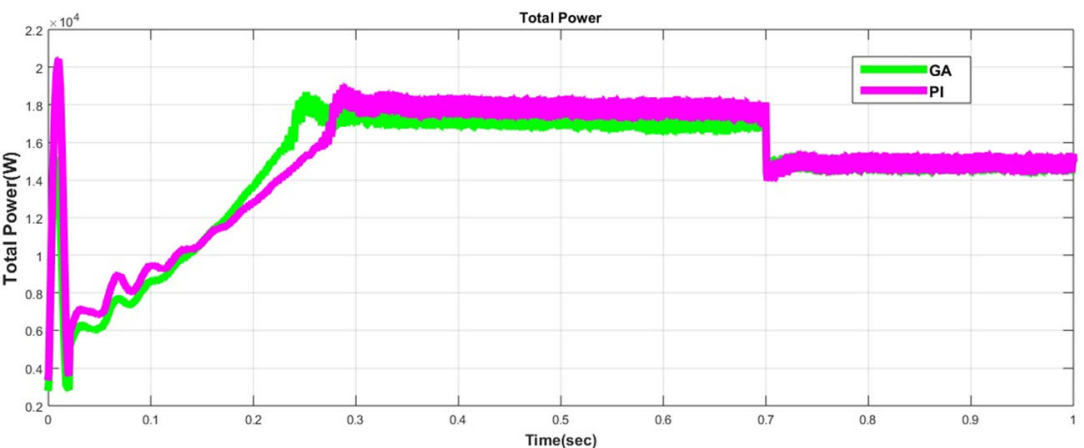

Table 1 Power rating of different sources in hybrid DGS

\begin{tabular}{ll}
\hline Energy Source & Power rating $(\mathbf{k W})$ \\
\hline PV system & $4.5 \mathrm{~kW}$ \\
Wind turbine & $2.5 \mathrm{~kW}$ \\
Fuel Cell & $3.0 \mathrm{~kW}$ \\
Battery & $6.0 \mathrm{~kW}$ \\
\hline
\end{tabular}

Table 2 Statistical analysis of proposed with existing techniques

\begin{tabular}{llll}
\hline Solution Methods & Mean & Median & SD \\
\hline Base & 1.0935 & 1.0159 & 0.1504 \\
PI & 1.3372 & 1.2558 & 0.1323 \\
Fuzzy & 1.4844 & 1.3862 & 0.1482 \\
GA & 1.5784 & 1.4892 & 0.5883 \\
\hline
\end{tabular}


results, during variations in the load under balanced and unbalanced supply of system, the proficiency of the proposed model is not affected, then the output power of different sources are almost constant and maintains the system stability. The effectiveness of proposed approach is evaluated with other existing systems like PI. From the comparative analysis, the settling time, the rise time and the maximum overshoot time are significantly decreased by proposed approach compared to existing method. The proposed controller is highly effectual and significantly decreases distortion compared to existing strategies.

Data Availability Statement Data sharing not applicable to this article as no datasets were generated or analysed during the current study.

\section{Declarations}

Conflict of Interest The authors declare no competing interests.

\section{References}

1. Camacho A, Castilla M, Miret J, Borrell A, de Vicuña LG (2014a) Active and reactive power strategies with peak current limitation for distributed generation inverters during unbalanced grid faults. IEEE Trans Ind Electron 62(3):1515-1525

2. Camacho A, Castilla M, Miret J, Guzman R, Borrell A (2014b) Reactive power control for distributed generation power plants to comply with voltage limits during grid faults. IEEE Trans Power Electron 29(11):6224-6234

3. El-Fergany A (2016) Multi-objective allocation of multi-type distributed generators along distribution networks using backtracking search algorithm and fuzzy expert rules. Electric power components and systems 44(3):252-267

4. Et-Taoussi M, Ouadi H, Chakir HE (2019) Hybrid optimal management of active and reactive power flow in a smart microgrid with photovoltaic generation. Microsyst Technol 25(11):40774090

5. Galiveeti HR, Goswami AK, Choudhury NB (2018) Impact of plug-in electric vehicles and distributed generation on reliability of distribution systems. Engineering science and technology, an international journal 21(1):50-59

6. Hashemi-Dezaki H, Askarian-Abyaneh H, Haeri-Khiavi H (2016) Impacts of direct cyber-power interdependencies on smart grid reliability under various penetration levels of microturbine/wind/solar distributed generations. IET Generation, Transmission \& Distribution 10(4):928-937

7. Hassan AA, Fahmy FH, Nafeh AE, Abu-elmagd MA (2017) Genetic single objective optimisation for sizing and allocation of renewable DG systems. International Journal of Sustainable Energy 36(6):545-562

8. Huy PD, Ramachandaramurthy VK, Yong JY, Tan KM, Ekanayake JB (2020) Optimal placement, sizing and power factor of distributed generation: a comprehensive study spanning from the planning stage to the operation stage. Energy. 195:117011

9. Lin R, Ye Z, Wu B (2020) The application of hydrogen and photovoltaic for reactive power optimization. Int J Hydrog Energy 45(17):10280-10291
10. Lingamuthu R, Mariappan R (2019) Power flow control of grid connected hybrid renewable energy system using hybrid controller with pumped storage. Int J Hydrog Energy 44(7):3790-3802

11. Marzband M, Ardeshiri RR, Moafi M, Uppal H (2017) Distributed generation for economic benefit maximization through coalition formation-based game theory concept. International Transactions on Electrical Energy Systems. 27(6):e2313

12. Mayer MJ, Szilágyi A, Gróf G (2020) Environmental and economic multi-objective optimization of a household level hybrid renewable energy system by genetic algorithm. Appl Energy 269:115058

13. Mohanty R, Pradhan AK (2017) Protection of smart DC microgrid with ring configuration using parameter estimation approach. IEEE Transactions on Smart Grid 9(6):6328-6337

14. Montoya OD, Gil-González W, Grisales-Noreña LF (2020) An exact MINLP model for optimal location and sizing of DGs in distribution networks: a general algebraic modeling system approach. Ain Shams Engineering Journal. 11(2):409-418

15. Mythili S, Thiyagarajah K, Rajesh P, Shajin FH (2020) Ideal position and size selection of unified power flow controllers (UPFCs) to upgrade the dynamic stability of systems: an antlion optimiser and invasive weed optimisation algorithm. HKIE Trans 27(1):25-37

16. Odou OD, Bhandari R, Adamou R (2020) Hybrid off-grid renewable power system for sustainable rural electrification in Benin. Renewable Energy.145:1266-79

17. Omar AI, Ali ZM, Al-Gabalawy M, Abdel Aleem SHE, AlDhaifallah M (2020) Multi-objective environmental economic dispatch of an electricity system considering integrated natural gas units and variable renewable energy sources. Mathematics. 8(7): 1100

18. Orlov D (2016) Smooth and proper noncommutative schemes and gluing of DG categories. Adv Math 302:59-105

19. Peesapati R, Yadav VK, Kumar N (2018) Flower pollination algorithm based multi-objective congestion management considering optimal capacities of distributed generations. Energy. 147:980-994

20. Pinto SJ, Panda G, Peesapati R (2017) An implementation of hybrid control strategy for distributed generation system interface using Xilinx system generator. IEEE Transactions on Industrial Informatics 13(5):2735-2745

21. Prabha DR, Jayabarathi T (2016) Optimal placement and sizing of multiple distributed generating units in distribution networks by invasive weed optimization algorithm. Ain Shams Engineering Journal 7(2):683-694

22. Rajesh P, Shajin F (2020) A multi-objective hybrid algorithm for planning electrical distribution system. European Journal of Electrical Engineering 22(4-5):224-509

23. Ramadan HS, Bendary AF, Nagy S (2017) Particle swarm optimization algorithm for capacitor allocation problem in distribution systems with wind turbine generators. Int J Electr Power Energy Syst 84:143-152

24. Rawa M, Abusorrah A, Bassi H, Mekhilef S, Ali ZM, Aleem SH, Hasanien HM, Omar AI. (2021) Economical-technicalenvironmental operation of power networks with wind-solarhydropower generation using analytic hierarchy process and improved grey wolf algorithm. Ain Shams Eng. J

25. Reddy PD, Reddy VV, Manohar TG (2017) Whale optimization algorithm for optimal sizing of renewable resources for loss reduction in distribution systems. Renewables: wind, water, and solar $4(1): 1-3$

26. Sarker J, Goswami SK (2016) Optimal location of unified power quality conditioner in distribution system for power quality improvement. Int J Electr Power Energy Syst 83:309-324

27. Shajin F, Rajesh P. (2020) Trusted secure geographic routing protocol: outsider attack detection in mobile ad hoc networks by adopting trusted secure geographic routing protocol. International Journal of Pervasive Computing and Communications 
28. Srinivas M, Hussain I, Singh B (2016) Combined LMS-LMFbased control algorithm of DSTATCOM for power quality enhancement in distribution system. IEEE Trans Ind Electron 63(7): $4160-4168$

29. Sultana U, Khairuddin AB, Mokhtar AS, Zareen N, Sultana B (2016) Grey wolf optimizer based placement and sizing of multiple distributed generation in the distribution system. Energy. 111:525536

30. Sultana U, Khairuddin AB, Sultana B, Rasheed N, Qazi SH, Malik NR (2018) Placement and sizing of multiple distributed generation and battery swapping stations using grasshopper optimizer algorithm. Energy. 165:408-421

31. Suresh MC, Belwin EJ (2018) Optimal DG placement for benefit maximization in distribution networks by using dragonfly algorithm. Renewables: Wind, Water, and Solar 5(1):1-8

32. Thota MK, Shajin FH, Rajesh P. (2020) Survey on software defect prediction techniques. International journal of applied science and engineering. 17;331-344

33. Vatani M, Alkaran DS, Sanjari MJ, Gharehpetian GB (2016) Multiple distributed generation units allocation in distribution network for loss reduction based on a combination of analytical and genetic algorithm methods. IET Generation, Transmission \& Distribution. 10(1):66-72
34. VC VR (2018) Optimal renewable resources placement in distribution networks by combined power loss index and whale optimization algorithms. Journal of Electrical Systems and Information Technology 5(2):175-191

35. Yammani C, Maheswarapu S, Matam SK (2016a) A multiobjective shuffled bat algorithm for optimal placement and sizing of multi distributed generations with different load models. Int J Electr Power Energy Syst 79:120-131

36. Yammani C, Maheswarapu S, Matam SK (2016b) Optimal placement and sizing of distributed generations using shuffled bat algorithm with future load enhancement. International Transactions on Electrical Energy Systems 26(2):274-292

37. Yao L, Yang B, Cui H, Zhuang J, Ye J, Xue J (2016) Challenges and progresses of energy storage technology and its application in power systems. Journal of Modern Power Systems and Clean Energy 4(4):519-528

38. Zheng Y, Dong ZY, Meng K, Yang H, Lai M, Wong KP (2017) Multi-objective distributed wind generation planning in an unbalanced distribution system. CSEE Journal of power and energy systems 3(2):186-195

Publisher's Note Springer Nature remains neutral with regard to jurisdictional claims in published maps and institutional affiliations. 